\title{
Bacteraemia and seeding of capsulate Bacteroides spp. and anaerobic cocci
}

\author{
I. BROOK*
}

Naval Medical Research Institute, Bethesda, MD 20814, USA

\begin{abstract}
Summary. The effect of capsulation on the ability of Bacteroides fragilis, $B$. asaccharolyticus and anaerobic gram-positive cocci to induce bacteraemia and seeding to various organs was investigated. The test species were injected into mice subcutaneously alone, or mixed with other aerobic or facultative organisms. Capsulate anaerobes were isolated more frequently from the blood, spleen, liver, and kidneys of infected animals than were non-capsulate organisms. After injection of single anaerobic strains, capsulate organisms were recovered from $163(39 \%)$ of 420 animals; non-capsulate anaerobes were recovered from only $14(3 \%)$ of 420 animals. After injection of $B$. fragilis mixed with aerobic or facultative organisms, the capsulate $B$. fragilis strain was isolated more often and for longer periods than the non-capsulate strain. Capsulate $B$. fragilis was also recovered more often 5 days after injection with other organisms, than when injected alone. These data demonstrate that capsulate Bacteroides spp. and anaerobic gram-positive cocci are more virulent than noncapsulate strains in single and mixed infections.
\end{abstract}

\section{Introduction}

Anaerobic bacteria are isolated from $5-15 \%$ of cases of bacteraemia (Finegold, 1977) and are particularly common in polymicrobial bacteraemia associated with abscesses (Brook et al., 1980). Recent studies have established the increased virulence of capsulate Bacteroides spp. (Kasper, 1976; Onderdonk et al., 1977; Brook et al., 1983; Brook and Walker, 1984a), in comparison with noncapsulate strains, and the role of anaerobic grampositive cocci (AGPC) (Brook and Walker, 1984b) in subcutaneous abscesses.

The role of capsular material in the systemic spread of anaerobic bacteria has not been defined. For this reason a subcutaneous abscess model in mice was used to determine the effect of capsulation on the ability of Bacteroides spp. and AGPC to induce bacteraemia and seeding to various organs. The effect of capsulation on previously non-capsulate strains was determined by injecting each of these alone or mixed with aerobic or facultative organisms.

Received 31 Dec. 1985; revised version accepted 8 May 1986. * Request for offprints should be sent to: Dr I. Brook, Experimental Hematology Department, Armed Forces Radiobiology Research Institute, Bethesda, MD 20814-5145, USA.

\section{Materials and methods}

\section{Organisms}

All organisms were recent clinical isolates that had been stored frozen in skimmed milk at $-70^{\circ} \mathrm{C}$. The anaerobic organisms included one strain each from seven bacterial species: Peptostreptococcus magnus, Pstr. asaccharolyticus, Pstr. prevoti, Pstr. micros, Pstr. anaerobius, Bacteroides fragilis and $B$. asaccharolyticus. The facultative or aerobic organisms were one strain each of group-A $\beta$-hemolytic Streptococcus, group-D Streptococcus, Staphylococcus aureus, Klebsiella pneumoniae, Escherichia coli, Proteus mirabilis, Pseudomonas aeruginosa and Haemophilus influenzae type b. They were identified by conventional methods (Lennette et al., 1980; Sutter et al., 1980).

\section{Capsular staining of the test strains}

The presence of capsules was established by Hiss's stain (Lennette et al., 1980) and confirmed by electron microscopy after staining with ruthenium red (Kasper, 1976). The strains of Bacteroides spp. and AGPC were originally $<1 \%$ capsulate (defined in this study as non-capsulate). Cultures in which at least $50 \%$ of the organisms had capsules (defined as capsulate) were prepared from the non-capsulate organisms by injecting them subcutaneously with $K$. pneumoniae to produce abscesses as previously described (Brook et al., 1983). Pus from these abscesses was removed and cultured 10 days after injection and were found to contain at least $50 \%$ capsulate 
forms of these organisms. K. pneumoniae, S. aureus, groups $\mathrm{A}$ and $\mathrm{D}$ streptococci, and $H$. influenzae were capsulate before and after their injection into the mice. Ruthenium red staining demonstrated a homogenous polysaccharide capsule external to the cell wall. E. coli, $P$. mirabilis, and $P$. aeruginosa were non-capsulate.

\section{Animals}

Male Swiss albino mice weighing 20-25 g were obtained from the Naval Medical Research Institute mouse colony (NMRI/NIH-CV). They were raised in conventional conditions.

\section{Abscess formation}

The bacteria were grown anaerobically or aerobically on sheep-blood-agar plates made with Brain Heart Infusion Base (BHI; Difco). Mice were each given subcutaneous injections in the right groin of $0.1 \mathrm{ml}$ of the appropriate bacteria suspended in saline $\left(10^{8}\right.$ bacteria). This dose of a single organism would induce subcutaneous abscesses almost without mortality (Brook et al., 1983; Brook and Gober, 1983). Sizes of individual abscesses were determined during necropsy on days 1, 3, 5 and 7 after injection, at which time the abscesses had neither decreased in size nor resolved. Although the volume of abscesses could st be determined accurately, their size was estimated by measuring with calipers two perpendicular diameters representing maximum length and width. Assuming that the abscess is an irregular prolate spheroid, the product of the length and width is approximately proportional to the outer surface of the abscess. This product, expressed as $\mathrm{mm}^{2}$, was arbitrarily selected as the means of comparison.

\section{Examination of abscesses, organs and blood}

Animals were killed by cervical dislocation. The spleen, liver, and the left kidney were removed aseptically; the spleen, kidney, and one lobe of the liver were immediately homogenised and inoculated on to media. Blood was obtained by open heart puncture and $0.3-0.5 \mathrm{ml}$ was immediately plated. The site and histology of the primary abscesses were confirmed in two animals in each experimental group by staining with haematoxylin and eosin. Pus was diluted in $1 \mathrm{ml}$ of enriched BHI broth and inoculated on to media. Specimens were inoculated within $5 \mathrm{~min}$ of collection on to reduced as well as prereduced BHI-agar plates (Sutter et al., 1980). One plate from each source was incubated aerobically and the other was incubated anaerobically in an anaerobic jar at $37^{\circ} \mathrm{C}$. Bacterial growth on the plates was estimated semiquantitatively. Colonies were identified by Gram's stain and biochemical tests $48 \mathrm{~h}$ and $96 \mathrm{~h}$ after inoculation (Lennette et al., 1980; Sutter et al., 1980).

\section{Experimental design}

The ability of each bacterial strain to induce subcutaneous abscesses, bacteraemia and seeding of organs was monitored by injecting each bacterial strain into 25 mice. The effect of capsulation in mixed infections was studied by injecting each of the capsulate and non-capsulate $B$. fragilis strains in combination with aerobic and facultative bacteria into 30 mice. On days $1,3,5$ and 7 , five randomly selected mice from each group were killed and cultures of their spleens, livers, left kidneys, blood and abscesses, if present, were made. Cultures were not done of mice that were found dead because of the uncertainty of the effect of delay on bacterial growth. To evaluate mortality, each bacterial strain or combination of strains was injected into 20 mice. All experiments were done three times.

\section{Statistical analysis}

Analysis of the data was done with the $\chi^{2}$-square test.

\section{Results}

\section{Induction of abscesses}

After injection of single organisms, abscesses were induced by all the aerobic and facultative bacteria as well as by the capsulate anaerobic bacteria. However, these organisms did not produce abscesses on every occasion. Abscesses were observed in $456(76 \%)$ of the 600 animals given aerobic and facultative bacteria and in $462(88 \%)$ of the 525 given capsulate anaerobic bacteria. Abscesses developed in only $21(4 \%)$ of the 525 animals given the non-capsulate anaerobes alone.

Abscesses were induced in $564(94 \%)$ of the 600 mice given mixtures of the capsulate $B$. fragilis and other bacteria, compared with $504(84 \%)$ of the 600 animals given the non-capsulate strain and other bacteria. Abscesses formed within $24-36 \mathrm{~h}$ and their size increased gradually. Without antibiotic therapy, the abscesses caused by pure cultures at day 5 had outer surface areas of $80-200 \mathrm{~mm}^{2}$, and the outer surface areas of abscesses caused by two organisms were $90-300 \mathrm{~mm}^{2}$.

\section{Histopathological examination of abscesses}

A fibrous encapsulated collection of material that contained bacteria and polymorphonuclear leukocytes was observed in abscesses caused by all single organisms as well as by all combinations of organisms.

\section{Recovery of organisms from abscesses}

Anaerobic bacteria were recovered from 434 (94\%) of 462 abscesses in the animals given pure cultures of capsulate anaerobes, and from $18(86 \%)$ 
of the 21 abscesses in animals given non-capsulate anaerobes. Aerobic or facultative bacteria were isolated from $438(96 \%)$ of the 456 abscesses induced by single aerobic or facultative bacteria.

From abscesses induced by mixtures of capsulate $B$. fragilis and aerobic or facultative bacteria, $B$. fragilis was recovered from $446(79 \%)$ of the 564 abscesses, and the aerobic or facultative species were isolated from $485(86 \%)$. From abscesses induced by mixtures of non-capsulate $B$. fragilis and aerobic or facultative bacteria, $B$. fragilis was recovered from $312(62 \%)$ of the 504 abscesses, and the aerobic or facultative species were isolated from $454(90 \%)$. The $B$. fragilis recovered from these abscesses was capsulate in $262(84 \%)$ of the 312 instances.

Recovery of anaerobic bacteria from blood, spleen, liver and kidney

In most animals from which organisms were recovered, identical bacteria were recovered concomitantly from all of the sites cultured (blood, spleen, liver and kidney). For this reason, the number of animals rather than the number of sites was chosen to represent the data. When injected alone, capsulate Bacteroides spp. and AGPC were isolated more frequently and for longer periods

Table I. Recovery of bacteria from the organs (liver, spleen and kidney) of mice given injection of single capsulate or non-capsulate strains

\begin{tabular}{|c|c|c|c|c|c|c|}
\hline \multirow[b]{2}{*}{ Test species } & & \multicolumn{5}{|c|}{$\begin{array}{l}\text { Number of mice* from } \\
\text { which bacteria were re- } \\
\text { covered on days } 1-7 \\
\text { after injection }\end{array}$} \\
\hline & & 1 & 3 & 5 & 7 & Total \\
\hline \multirow[t]{2}{*}{ B. fragilis } & cap + & 12 & 13 & 5 & 1 & 31 \\
\hline & cap - & 2 & 1 & 0 & 0 & 3 \\
\hline \multirow[t]{2}{*}{ B. asaccharolyticus } & cap + & 8 & 10 & 5 & 2 & 25 \\
\hline & cap - & 1 & 0 & 0 & 0 & 1 \\
\hline \multirow[t]{2}{*}{ Pstr, magnus } & cap + & 11 & 10 & 1 & 0 & 22 \\
\hline & cap - & 2 & 2 & 0 & 0 & 4 \\
\hline \multirow[t]{2}{*}{ Pstr. asacchrolyticus } & cap + & 11 & 13 & 5 & 0 & 29 \\
\hline & cap - & 2 & 1 & 0 & 0 & 3 \\
\hline \multirow[t]{2}{*}{ Pstr. prevotii } & cap + & 9 & 7 & 0 & 0 & 16 \\
\hline & cap - & 1 & 0 & 0 & 0 & 1 \\
\hline \multirow[t]{2}{*}{ Pstr. micros } & cap + & 12 & 10 & 6 & 0 & 28 \\
\hline & cap - & 1 & 1 & 0 & 0 & 2 \\
\hline \multirow[t]{2}{*}{ Pstr. anaerobius } & cap + & 9 & 3 & 0 & 0 & 12 \\
\hline & cap - & 0 & 0 & 0 & 0 & 0 \\
\hline
\end{tabular}

cap $+=$ Capsulate organisms; cap $-=$ non-capsulate organisms.

* A total of 15 mice were killed in each group each day. than were the non-capsulate strains (table I). Capsulate strains were recovered from $163(39 \%)$ of the 420 animals, compared with recovery of noncapsulate strains from $14(3 \%)$. Capsulate $B$. fragilis was recovered for longer periods after injection with facultative or aerobic bacteria, than when capsulate $B$. fragilis was injected alone (table II). Five days after injection, capsulate $B$. fragilis was isolated from 78 of the 120 mice given $B$. fragilis and other flora, compared with its recovery from 5 of the 15 animals given $B$. fragilis alone $(\mathrm{p}<0.05)$.

A similar difference, although not statistically significant, was observed on the seventh day after injection; capsulate $B$. fragilis was recovered from 32 of the 120 mice given $B$. fragilis and other bacteria, compared with from 2 of the 15 given capsulate $B$. fragilis alone $(\mathrm{p}<0 \cdot 1)$. No increase in

Table II. Recovery of bacteria from the organs (liver, spleen and kidney) of mice given injections of $B$. fragilis and facultative or aerobic bacteria

\begin{tabular}{|c|c|c|c|c|}
\hline \multirow[b]{2}{*}{ Bacteria injected } & \multicolumn{4}{|c|}{$\begin{array}{l}\text { Number of mice* from } \\
\text { which } B \text {. fragilis/other } \\
\text { bacteria were recovered } \\
\text { on day }\end{array}$} \\
\hline & 1 & 3 & 5 & 7 \\
\hline BF $(+)$ alone & 12 & 13 & 5 & 1 \\
\hline $\mathrm{BF}(-)$ alone & 2 & 1 & 0 & 0 \\
\hline$S$. aureus alone & 12 & 6 & 1 & 0 \\
\hline S. aureus \& BF (+) & $11 / 14$ & $13 / 10$ & $9 / 6$ & $4 / 3$ \\
\hline S. aureus \& BF (-) & $0 / 14$ & $2 / 13$ & $0 / 4$ & $0 / 2$ \\
\hline Gr. A Streptococcus alone & 10 & 3 & 0 & 0 \\
\hline Gr. A Streptococcus \& BF (+) & $11 / 10$ & $12 / 5$ & $11 / 4$ & $4 / 0$ \\
\hline Gr. A Streptococcus \& BFU(-) & $0 / 10$ & $0 / 4$ & $0 / 0$ & $0 / 0$ \\
\hline Gr. D Streptococcus & 11 & 8 & 5 & 0 \\
\hline Gr. D Streptococcus \& BF (+) & $9 / 12$ & $12 / 6$ & $10 / 8$ & $3 / 1$ \\
\hline Gr. D Streptococcus \& BF (-) & $1 / 13$ & $0 / 7$ & $0 / 5$ & $0 / 0$ \\
\hline H. influenzae alone & 7 & 3 & 1 & 0 \\
\hline H. influenzae \& BF (+) & $9 / 10$ & $8 / 10$ & $10 / 3$ & $3 / 0$ \\
\hline H. influenzae \& BF $(-)$ & $0 / 8$ & $0 / 7$ & $0 / 2$ & $0 / 0$ \\
\hline$K$. pneumoniae alone & 10 & 9 & 8 & 4 \\
\hline$K$. pneumoniae \& BF $(+)$ & $12 / 12$ & $13 / 11$ & $10 / 10$ & $5 / 8$ \\
\hline K. pneumoniae \& BF (-) & $0 / 10$ & $0 / 10$ & $0 / 6$ & $0 / 3$ \\
\hline E. coli alone & 8 & 6 & 4 & 0 \\
\hline E. coli \& BF $(+)$ & $10 / 12$ & $9 / 11$ & $7 / 13$ & $4 / 2$ \\
\hline E. coli \& BF (-) & $2 / 13$ & $0 / 8$ & $0 / 6$ & $0 / 0$ \\
\hline$P$. mirabilis alone & 12 & 8 & 5 & 1 \\
\hline P. mirabilis \& $\mathrm{BF}(+)$ & $8 / 12$ & $6 / 10$ & $10 / 9$ & $3 / 2$ \\
\hline P. mirabilis \& $\mathrm{BF}(-)$ & $0 / 11$ & $1 / 10$ & $1 / 6$ & $0 / 0$ \\
\hline Ps. aeruginosa alone & 15 & 13 & 10 & 6 \\
\hline Ps. aeruginosa \& BF (+) & $10 / 14$ & $13 / 10$ & $11 / 10$ & $6 / 4$ \\
\hline Ps. aeruginosa \& $\mathrm{BF}(-)$ & $0 / 15$ & $1 / 12$ & $0 / 11$ & $0 / 5$ \\
\hline
\end{tabular}

$\mathrm{BF}(+)=$ Capsulate $B$. fragilis; $\mathrm{BF}(-)=$ non-capsulate $B$. fragilis.

* A total of 15 mice were killed from each group each day. 
the recovery rate of non-capsulate $B$. fragilis was observed when it was injected with other bacteria.

Facultative or aerobic bacteria were generally recovered more often and for longer periods after injection with capsulate $B$. fragilis, than when they were injected alone (table II). Higher rates of recovery of facultative or aerobic bacteria after injection mixed with capsulate $B$. fragilis were observed only with $S$. aureus, group-A Streptococcus, $K$. pneumoniae and $E$. coli $(\mathrm{p}<0.05)$. A significant increase in the recovery rate after injection mixed with capsulate $B$. fragilis compared with the rate after injection mixed with non-capsulate $B$. fragilis was observed only with $E$. coli and $K$. pneumoniae.

\section{Mortality}

When mortality was noted, it occurred within the first $72 \mathrm{~h}$ after injection. No deaths occurred after injection of the Bacteroides spp., H. influenzae, Group-D streptococci, or AGPC alone. The mortality after injection of $S$. aureus alone was $3(5 \%)$ of 60 , group-A streptococci 2 of $60(1 \%), K$. pneumoniae 4 of $60(7 \%)$, E. coli 8 of $60(13 \%), P$. mirabilis 5 of $60(8 \%)$ and Ps. aeruginosa 5 of $60(8 \%)$.

No increase in mortality was noted after injection of mixtures of non-capsulate anaerobic organisms and the other organisms (table III). However, a significant increase in mortality was noted when capsulate $B$. fragilis was injected mixed with other organisms in 6 of 8 combinations; similar results were obtained with capsulate $B$. asaccharolyticus in 7 of 8 instances. An increase in mortality was noted with 7 of the 40 combinations of the capsulate AGPC and the other organisms. The aerobic or facultative bacteria most often associated with increased mortality were group-D streptococci in 5 of 7 combinations with anaerobes, $P s$. aeruginosa in 4 of 8 , and $S$. aureus in 3 of 8 . Although in many combinations there were no significant individual differences in the mortality rates, comparison of the total mortality for each facultative or aerobic species was significant in all instances (table III).

\section{Discussion}

This study highlights the importance of capsulate Bacteroides spp. and AGPC in increasing the mortality associated with bacteraemia and seeding to different organs. The presence of capsular material made these organisms more virulent than their non-capsulate counterparts. Similar virulence characteristics have also been observed in other bacterial species, such as Str. pneumoniae (Wood and Smith, 1949) and H. influenzae (Chandler et al.,

Table III. Mortality of mice after inoculation with anaerobic bacteria and facultative or aerobic bacteria*

\begin{tabular}{|c|c|c|c|c|c|c|c|c|c|}
\hline \multirow[b]{2}{*}{ Anaerobic organism } & & \multicolumn{8}{|c|}{ Number of deaths* in mice given the test anaerobe plus } \\
\hline & & $\begin{array}{c}S . \\
\text { aureus }\end{array}$ & $\begin{array}{c}\text { Group A } \\
\text { Streptococcus }\end{array}$ & $\begin{array}{c}\text { Group D } \\
\text { Streptococcus }\end{array}$ & $\begin{array}{c}H . \\
\text { influenzae }\end{array}$ & $\begin{array}{c}K . \\
\text { pneumoniae }\end{array}$ & $\begin{array}{c}E . \\
\text { coli }\end{array}$ & $\begin{array}{c}P . \\
\text { mirabilis }\end{array}$ & $\begin{array}{c}\text { Ps. } \\
\text { aeruginosa }\end{array}$ \\
\hline \multirow[t]{2}{*}{ B. fragilis } & cap + & 11 & $16+$ & $13 \dagger$ & 6 & $19+$ & $19 \dagger$ & $17 \dagger$ & $22 \div$ \\
\hline & cap - & 4 & 5 & 2 & 3 & 6 & 8 & 5 & 7 \\
\hline \multirow[t]{2}{*}{ B. asaccharolyticus } & cap + & $12 \dagger$ & $14 \dagger$ & $10 \dagger$ & 9 & $15 \dagger$ & $21 \dagger$ & $15 \dagger$ & $20 \dagger$ \\
\hline & cap - & 2 & 4 & 3 & 2 & 5 & 7 & 7 & 8 \\
\hline \multirow[t]{2}{*}{ Pstr. magnus } & cap + & 2 & 3 & $9+$ & 6 & 7 & 10 & 9 & 7 \\
\hline & cap - & 1 & 0 & 0 & 1 & 6 & 8 & 8 & 4 \\
\hline \multirow[t]{2}{*}{ Pstr. asaccharo. } & cap + & $13 \dagger$ & 9 & $7 \dagger$ & 3 & 6 & 11 & 3 & 14 \\
\hline & cap - & 3 & 1 & 0 & 0 & 3 & 10 & 4 & 6 \\
\hline \multirow[t]{2}{*}{ Pstr. prevoti } & cap + & 10 & 1 & $6 \dagger$ & 1 & 9 & 10 & 5 & 15 \\
\hline & cap - & 5 & 2 & 0 & 1 & 4 & 7 & 6 & 9 \\
\hline \multirow[t]{2}{*}{ Pstr. micros } & cap + & $14 \dagger$ & 8 & 5 & 1 & 3 & 12 & 3 & $15 \dagger$ \\
\hline & cap - & 2 & 3 & 2 & 2 & 1 & 8 & 3 & 6 \\
\hline \multirow[t]{2}{*}{ Pstr. anaerobius } & cap + & 7 & 5 & 6 & 2 & 4 & 8 & 8 & $17 \dagger$ \\
\hline & cap - & 2 & 0 & 1 & 0 & 2 & 6 & 7 & 4 \\
\hline \multirow{2}{*}{\multicolumn{2}{|c|}{$\begin{array}{l}\text { Total capsulate anaerobes } \\
\text { Total non-capsulate anaer- } \\
\text { obes }\end{array}$}} & $69 \ddagger$ & $56 \ddagger$ & $46 \ddagger$ & $28 \%$ & $63 \ddagger$ & $91 \ddagger$ & $60^{\dagger}$ & $110 t$ \\
\hline & & 19 & 15 & 8 & 9 & 27 & 54 & 40 & 44 \\
\hline
\end{tabular}

cap $+=$ Capsulate strain; cap $-=$ non-capsulate strain.

* A total of 60 mice was given each combination.

$\dagger=\mathrm{p}<0.05$ compared with non-capsulate strains.

$\ddagger=\mathrm{p}<0.001$ compared with non-capsulate strains. 
1937); however, this phenomenon has not been previously described in Bacteroides spp. and AGPC. Onderdonk et al. (1974) detected bacteraemia due to $B$. fragilis only during the first few hours after intraperitoneal injection of $B$. fragilis and $E$. coli in rats. However, their model represented an intra-abdominal infection, whereas ours was a subcutaneous infection. Bennion et al. (1984) induced colonic ischaemia in dogs and this caused prolonged and persistent bacteraemia due to $B$. fragilis and other anaerobic bacteria.

Several studies provide support for the pathogenic role of capsulate anaerobes in infectious processes. A higher recovery rate of capsulate anaerobic bacteria was noted from acutely inflamed tonsils (Brook and Gober, 1983) and orofacial abscesses (Brook, 1986) than from the normal oral flora.

Onderdonk et al. (1977), Brook et al. (1983) and Brook and Walker $(1984 a, 1984 b)$ correlated the virulence of Bacteroides spp. and AGPC with the presence of capsules. Injection of capsulate anaerobes alone resulted in abscess formation in most animals, whereas non-capsulate species seldom caused abscesses unless they were combined with an aerobic organism. Heat-killed capsulate strains of $B$. fragilis or purified capsular polysaccharide alone, but not capsular polysaccharide from $E$. coli, resulted in formation of intra-abdominal abscesses (Onderdonk et al., 1977). Simon et al. (1982) showed that capsulate strains of Bacteroides were more resistant to neutrophil-mediated killing than were non-capsulate strains. These investigations provide evidence that the capsular polysaccharide of $B$. fragilis is an important virulence factor.

We have previously observed the emergence of capsulate Bacteroides spp. and AGPC in mixed infections with other flora (Brook et al., 1983; Brook and Walker, 1984a, 1984b). With few exceptions, possession of a capsule made these organisms more important in vivo than their aerobic counterparts. Although non-capsulate organisms did not induce abscesses, many of the strains (which had only minimal numbers of capsulate organisms) when injected mixed with other bacteria, survived in the abscesses and became predominantly capsulate. These capsulate strains were thereafter able to induce abscesses when injected alone. This phenomenon may help to explain how non-pathogenic organisms that are part of the normal host flora can become pathogens. It may also explain the importance of anaerobic organisms in chronic infections and in abscess formation, because the process of capsulation took 10-14 days. The non-capsulate strains used in our study were clinical strains that had probably lost their capsules after in-vitro passages and storage, but were able to re-acquire the capsule after animal passage.

The present study confirms our previous observation of the synergy between Bacteroides spp. and AGPC and the other flora present with them in mixed infections (Brook et al., 1984). Synergy between aerobic and anaerobic bacteria has long been recognised in various clinical infections (Gorbach and Bartlett, 1974; Finegold, 1977). In several animal studies, a mixed inoculum of anaerobic and aerobic bacteria produced sepsis that could not be induced by either component alone (Gorbach and Bartlett, 1974; Onderdonk et al., 1974; Kelly, 1977, 1978). The role of capsulation was, however, not considered in these studies.

Altemeier (1942) demonstrated the pathogenicity of bacterial isolates isolated from peritoneal cultures after rupture of the appendix. Pure cultures of individual isolates were relatively innocuous when implanted subcutaneously in animals, but combinations of facultative anaerobic and anaerobic strains greatly increased virulence. Similar observations were reported by Meleney et al. (1932) and Hite et al. (1949). Several hypotheses have been proposed to explain microbial synergy. When this phenomenon occurs in mixtures of aerobic and anaerobic flora, it may be due to protection from phagocytosis and intracellular killing (Ingham et al., 1977, 1981), supply of essential growth factors (Lev et al., 1971), and lowering of oxidation-reduction potential in host tissues (Mergenhagen et al., 1958).

The increased virulence of capsulate anaerobic bacteria and their synergic potential with other flora is believed to be mediated through increased resistance of these bacteria to phagocytosis and killing by polymorphonuclear leukocytes and macrophages (Ingham et al., 1977, 1981; Namavar et al., 1983, 1984; Connolly et al., 1984). Furthermore, the capsulate bacteria have been shown to decrease phagocytosis of other organisms associated with them in mixed infections.

Ingham et al. $(1977,1981)$ investigated the effect of Bacteroides spp. on the phagocytic killing of facultative species. Killing of $B$. fragilis and $P$. mirabilis in mixtures in vitro was impaired when the concentration of $B$. fragilis was $>10^{7} \mathrm{cfu} / \mathrm{ml}$ in the phagocytic system. Connolly et al. (1984) provided evidence that correlated the inhibition of in-vitro phagocytosis of $P$. mirabilis with the capsular polysaccharide of $B$. fragilis. $B$. gingivalis cells or culture supernates were shown to possess the greatest inhibitory effect amongst the Bacteroides species (Namavar et al., 1984). Supernates of cultures of $B$. fragilis group, $B$. melaninogenicus group, and $B$. 
gingivalis were shown to be capable of inhibiting the chemotaxis of leukocytes to the chemotactic factors of $P$. mirabilis (Namavar et al., 1983). Capsular material from $B$. melaninogenicus also inhibited phagocytosis and phagocytic killing of other microorganisms in an in-vitro system (Okuda and Takazoe, 1973).

Further studies are necessary to explain the increased virulence of capsulate Bacteroides spp. and AGPC, as expressed by persistent bacteraemia and seeding to different organs.

\section{REFERENCES}

Altemeier W A 1942 The pathogenicity of the bacteria of appendicitis peritonitis: an experimental study. Surgery 11:378.

Bennion R S, Wilson S E, Serota A I, Williams R A 1984 The role of gastrointestinal microflora in the pathogenesis of complications of mesenteric ischemia. Reviews of Infectious Diseases 6 Suppl:S132-S138.

Brook I 1986 Recovery of encapsulated anaerobic bacteria from orofacial abscesses. Journal of Medical Microbiology 22:171-176.

Brook I, Controni G, Rodriguez W J, Martin W J 1980 Anaerobic bacteremia in children. American Journal Disease Childhood 134:1052-1056.

Brook I, Gillmore J D, Coolbaugh J C, Walker R I 1983 Pathogenicity of encapsulated Bacteroides melaninogenicus group, Bacteroides oralis, and Bacteroides ruminocola subsp. brevis in abscesses in mice. Journal of Infection 7:218226.

Brook I, Gober A E 1983 Bacteroides melaninogenicus, its recovery from tonsils of children with acute tonsillitis, Archives of Otolaryngology 109:818-820.

Brook I, Hunter V, Walker R I 1984 Synergistic effects of Bacteroides, Clostridium, Fusobacterium, anaerobic cocci and aerobic bacteria on mortality and induction of subcutaneous abscesses in mice. Journal of Infectious Diseases 149:924-928.

Brook I, Walker R I $1984 a$ Significance of encapsulated Bacteroides melaninogenicus and Bacteroides fragilis groups in mixed infections. Infection and Immunity 44:12-15.

Brook I, Walker R I $1984 b$ Pathogenicity of anaerobic grampositive cocci. Infection and Immunity 45:320-324.

Chandler C A, Fothergill L D, Dingle J H 1937 Studies on Haemophilus influenzae. II. A comparative study of the virulence of smooth, rough, and respiratory strains of Haemophilus influenzae as determined by infection of mice with mucin suspensions of the organism. Journal of Experimental Medicine 66:789-799.

Connolly J C, McLean C, Tabaqchali S, 1984 The effect of capsular polysaccharide and lipopolysaccharide of Bacteroides fragilis on polymorph function and serum killing. Journal of Medical Microbiology 17:259-271.

Finegold S M 1977 Anaerobic bacteria in human disease. Academic Press, New York.

Gorbach S L, Bartlett J G 1974 Anaerobic infections. New England Journal of Medicine 290:1177-1184, 1237-1245, 1289-1294.

Ingham H R, Sisson P R, Middleton R L, Narang H K, Codd A A, Selkon J B 1981 Phagocytosis and killing of bacteria in
The opinions and assertions contained herein are the private ones of the writer and are not to be construed as official or reflecting the view of the Navy Department, the Naval Services at large, or the Defense Nuclear Agency.

Research was conducted according to the principles enunciated in the "Guide for the Care and Use of Laboratory Animals" prepared by the Institute of Laboratory Animal Resources, National Research Council.

J. E. Perry gave technical assistance, C. H. Dorsey performed the electron microscopy preparation, and Mariann Waldbillig gave secretarial assistance.

aerobic and anaerobic conditions. Journal of Medical Microbiology 14:391-399.

Ingham H R, Sisson P R, Tharagonnet D, Selkon J B, Codd A A 1977 Inhibition of phagocytosis in vitro by obligate anaerobes. Lancet 2:1252-1254.

Hite K E, Locke M, Hesseltine H C 1949 Synergism in experimental infections with nonsporulating anaerobic bacteria. Journal of Infectious Diseases 84:1-9.

Kasper D L 1976 Chemical and biological characterization of the lipopolysaccharide of Bacteroides fragilis subspecies fragilis. Journal of Infectious Diseases 134:59-66.

Kelly M J 1977 Aerobic and anaerobic mixtures of human pathogens: a rapid 4-plate counting technique. British Journal of Experimental Pathology 58:478-483.

Kelly M J 1978 The quantitative and histological demonstration of pathogenic synergy between Escherichia coli and Bacteroides fragilis in guinea-pig wounds. Journal of Medical Microbiology 11:513-523.

Lennette E H, Balows A, Hausler W J, Truant J P (eds) 1980 Manual of clinical microbiology, 3rd edn. American Society for Microbiology, Washington, DC.

Lev M, Keudell K C, Milford A F 1971 Succinate as a growth factor for Bacteroides melaninogenicus. Journal of Bacterio$\log y$ 108:175-178.

Meleney F L, Olpp J, Harvey H D, Jern H Z 1932 Peritonitis: synergism of bacteria commonly found in peritoneal exudates. Archives of Surgery 25:709-721.

Mergenhagen S E, Thonard J C, Scherp H W 1958 Studies on synergistic infections. I. Experimental infections with anaerobic streptococci. Journal of Infectious Diseases 103:33-44.

Namavar F, Verweij-van Vught A M J J, Bal M, van Steenbergen T J M, de Graaff J, MacLaren D M 1983 Effect of anaerobic bacteria on killing of Proteus mirabilis by human polymorphonuclear leukocytes. Infection and Immunity 40:930-935.

Namavar F, Verweij-van Vught A M J J, Vel W A C, Bal M, MacLaren D M 1984 Polymorphonuclear leukocyte chemotaxis by mixed anaerobic and aerobic bacteria. Journal of Medical Microbiology 18:167-172.

Okuda K, Takazoe I 1973 Antiphagocytic effects of the capsular structure of a pathogenic strain of Bacteroides melaninogenicus. Bulletin of the Tokyo Dental College 14:99-104.

Onderdonk A B, Kasper D L, Cisneros R L, Bartlett J B 1977 The capsular polysaccharide of Bacteroides fragilis as a virulence factor: comparison of the pathogenic potential of encapsulated and unencapsulated strains. Journal of Infectious Diseases 136:82-89.

Onderdonk A B, Weinstein W M, Sullivan N M, Bartlett J G, Gorbach S L 1974 Experimental intra-abdominal abscesses 
in rats: quantitative bacteriology of infected animals. Infection and Immunity 10:1256-1259.

Simon G L, Klempner M S, Kasper D L, Gorbach S L 1982

Alterations in opsonophagocytic killing by neutrophils of Bacteroides fragilis associated with animal and laboratory passage: effect of capsular polysaccharide. Journal of Infectious Diseases 145:72-77.
Sutter V L, Citron D M, Finegold S M (eds) 1980 Wadsworth anaerobic bacteriology manual, 3rd edn. The C. V. Mosby Co., St Louis.

Wood W B, Smith M R 1949 The inhibition of surface phagocytosis by capsular "slime layer" of Pneumococcus type III. Journal of Experimental Medicine 90:85-96. 